\title{
Influence of preanalytical variables on performance of delta-like protein 3 (DLL3) predictive immunohistochemistry
}

\author{
Teodora Radonic ${ }^{1}$ (D) S. Duin ${ }^{1}$ - W. Vos $^{1}$ • P. Kortman ${ }^{1}$ - Aeilko H. Zwinderman ${ }^{2}$ (D) E Erik Thunnissen ${ }^{1}$ (D)
}

Received: 8 April 2020 / Revised: 10 May 2020 / Accepted: 14 May 2020 / Published online: 2 June 2020

(C) The Author(s) 2020

\begin{abstract}
DLL3 might become a predictive immunohistochemical marker in small cell carcinoma of the lung (SCLC). We investigated the influence of pre-analytical handling of samples on the performance of DLL3 immunohistochemistry (IHC) using DLL3 SP347 ready to use assay (Ventana). DLL3 positive cell lines were subjected to different experimental conditions mimicking the preanalytical variation in daily clinical practice. Formalin fixation of $24 \mathrm{~h}$ led to the most optimal results of DLL3 IHC. Longstanding fixation in Cytolyt, methanol-based fixative for cytology samples, but also decalcification using a mix of formic- and hydrochloracid resulted in decreased DLL3 staining. Postponed staining of blanc slides for 3 months also decreased DLL3 IHC. Postponed fixation of the SCLC cell lines did not influence the performance of DLL3 IHC, although this might be different in the tissues than in the cell lines. In conclusion, different pre-analytical variables decrease the performance of DLL3 IHC. These findings are essential for implementing novel predictive immunohistochemical biomarkers in daily pathology practice.
\end{abstract}

Keywords DLL3 $\cdot$ Immunohistochemistry $\cdot$ Preanalytical variable $\cdot$ Formalin $\cdot$ Decalcification

\section{Introduction}

DLL3 emerged as a potential target in small cell lung cancer (SCLC) from gene expression studies. DLL3 is a member of a Notch ligand receptor family and in normal cells inhibits the Notch pathway $[1,2]$ which is frequently inactivated in SCLC [3]. DLL3 is overexpressed in most SCLC cases on cell membrane and intracytoplasmatically about 35 -fold compared to normal lung in the majority of patients with SCLC [4]. Moreover, DLL 3 is not expressed in the normal tissues in adults and is therefore an interesting therapeutic target in SCLC [4].

This article is part of the Topical Collection on Quality in Pathology

Electronic supplementary material The online version of this article (https://doi.org/10.1007/s00428-020-02848-y) contains supplementary material, which is available to authorized users.

Teodora Radonic

t.radonic@amsterdamumc.nl

1 Department of Pathology, Amsterdam University Medical Center, De Boelelaan, 1117 Amsterdam, The Netherlands

2 Department of Clinical Epidemiology and Biostatistics, Amsterdam University Medical Centers, Meibergdreef 9, 1105

AZ Amsterdam, The Netherlands
From the experience gained with PD-L1 as a widely used predictive IHC biomarker in pathology, it was recognized that preanalytical, analytical, and postanalytical variables can influence testing performance [5-8]. Pre-analytical variables in daily pathology practice include steps from the sample collection until start of fixation. Potentially, most important factors for the quality of the sample and those that can be influenced by the way of sample handling are (1) warm ischemia time (relevant for the resection specimens and starts from the blood supply cut off), (2) cold ischemia time (time from removal from the body until fixation) [8], (3) temperature at which fresh sample is kept during cold ischemia time [9], (4) type of fixative and decalcification [10], but also (5) tissue to fixative ratio [11]. In general, the possible effect of variation in prenanalytical variables on predictive biomarker testing is frequently mentioned in reviews [12,13], but detailed studies on this topic are sparse. Recently, in a tissue model experiment on the effect of delayed fixation, reduced IHC staining of several antibodies, including PD-L1 and cytokeratins, was found [8]. Moreover, in another study, the type and duration of decalcification were shown to drastically reduce the PD-L1 IHC intensity and the proportion of positive cells [10,14]. When PDL1 IHC intensities after decalcification were compared between two IHC clones (22C3 and E1L3N), there was a slight reduction in percentage of positive cells only for $22 \mathrm{C} 3$ clone 
while staining using E1L3N clone was stable [10]. Therefore, the knowledge of the effect of preanalytical variables on the performance of a predictive biomarker is essential for implementation in the clinical practice.

The aim of this study is to examine the influence of different clinically relevant preanalytical variables on the performance of DLL3 IHC. We assessed the effect of different fixatives, fixation times, delay in fixation, and use of a decalcification procedure.

\section{Methods}

\section{Cell lines and culture}

Three cell lines were used: NCI-H69 [H69] (ATCC® HTB119 ${ }^{\mathrm{TM}}$ ) human SCLC line reported to have a low DLL3 expression; NCI-H82 [H82] (ATCC® HTB175 ${ }^{\mathrm{TM}}$ ) human SCLC line reported to have a medium DLL3 expression, comparable with that in patient SCLC samples and A549 (ATCC@ CCL-185 ${ }^{\mathrm{TM}}$ ); and human non-small cell cancer line previously reported to have virtually no DLL3 expression (negative control) [15].

Three cell lines were separately grown under aseptic conditions in an incubator providing a humidified atmosphere of $5 \% \mathrm{CO} 2$ in air. All cell lines were used between 3 and 9 passages after thawing to ensure complete revival and routinely tested for mycoplasma. All cell lines were cultured in RPMI base media supplemented with $10 \%$ fetal bovine serum, $2 \mathrm{mM}$ L-glutamine, $10 \mathrm{mM}$ HEPES, $1 \mathrm{mM}$ sodium pyruvate, $4500 \mathrm{mg} / \mathrm{L}$ glucose, $1500 \mathrm{mg} / \mathrm{L}$ sodium bicarbonate, and $100 \mathrm{U} / \mathrm{mL}$ penicillin and $100 \mu \mathrm{g} / \mathrm{mL}$ streptomycin.

After sufficient cells were cultured, H69 and H82 were centrifuged and subsequently objected to different conditions as described below. A549 was first treated with trypsin, and two times washed in PBS. All three cell lines were embedded in agar gel, processed in TissueTek Xpress X120 (Sakura Finetek USA, Torrance, CA), and embedded in paraffin block.

\section{Preanalytical conditions}

In Table 1 all preanalytical conditions are presented. In the first phase, the optimal fixation time for two fixatives was determined. The fixatives were $10 \%$ neutral buffered formalin for tissues and Cytolyt®ThinPrep (Hologic Inc., Marlborough, MA, USA), a methanol-based medium for cytology specimens. After this step, the fixation medium and time were selected that resulted in highest DLL3 IHC staining as "golden standard" for the next steps. In order to examine whether formalin postfixation could modify DLL3 intensity after initial Cytolyt fixation, we tested two different times of Cytolyt fixation followed by two different times of formalin postfixation.
Table 1 Preanalytical conditions

\begin{tabular}{lllll}
\hline Preanalytical variable & & Times (h)* \\
\hline Fixation in formalin & & $3,24,48,72$ \\
Fixation in Cytolyt & & $3,24,48,72$ \\
Fixation in Cytolyt followed by formalin & & & \\
& Time in Cytolyt & 3 & 24 & 24 \\
& Subsequent time in formalin & 24 & 3 & 24 \\
Postponed fixation & & & & \\
& & Room temperature & $3,6,24$ \\
& $4{ }^{\circ} \mathrm{C}$ & $3,6,24$ \\
Postponed staining & & & \\
& & Room temperature & 1 week, \\
& & 3 months \\
& $4{ }^{\circ} \mathrm{C}$ & 1 week, \\
Decalcification Kris. & & 3 months \\
Decalcification Sakura & & 24,48 \\
\hline
\end{tabular}

*Unless otherwise specified

Kris. Kristensen

In the following phase, postponed fixation was examined. The cells were centrifuged, washed, and left without bovine serum and without fixative for 3,6 , and $24 \mathrm{~h}$ on room temperature and $4{ }^{\circ} \mathrm{C}$, respectively. Subsequently, cells were processed using the golden standard method which emerged from the previous step (24-h formalin fixation on room temperature).

Influence of decalcification was tested with two commonly used decalcification media:(1) 1:1 $8 \mathrm{~N}$-formic acid and 1-N sodium formate solution ( $\mathrm{pH}$ 2.2), also known as Kristensen and (2) Sakura Reagent TDE30 decalcifier. In line with the clinical practice specimens were first fixated and subsequently decalcified. Different fixation times $(3,24$, or $48 \mathrm{~h})$ in $10 \%$ buffered formalin were examined with subsequent longstanding decalcification for 24 or $48 \mathrm{~h}$.

Influence of postponed staining of blanc histological sections was examined, where the blancs were left on the room temperature or $4{ }^{\circ} \mathrm{C}$ for 1 week and 3 months, respectively.

The whole series of experiments (including growing the cell cultures) was performed in duplo.

\section{Immunohistochemistry}

From each block, $4-\mu \mathrm{m}$ thick sections were cut and mounted on positively charged glass slides and stained using DLL3 ready-to-use assay (clone SP347, Ventana, Roche, Tucson, AZ, USA), after pre-treatment with $\mathrm{CC} 1$ for $80 \mathrm{~min}$, and using the OptiView detection kit (Ventana) on a Benchmark Ultra slide staining instrument (Ventana), following the manufacturer's instructions. 
Staining intensity was scored using the $\mathrm{H}$-score (range 0 300 ). In short, the percentage of cells at each staining intensity level $(0,1+, 2+$, and $3+)$ is scored, and $\mathrm{H}$-score is calculated using the following formula: $1 \times(\%$ cells $1+)+2 \times(\%$ cells $2+)+3 \times(\%$ cells $3+)[16]$.

All slides were stained twice (in duplo staining) and scored by two investigators (in duplo reading).

\section{Statistics}

$\mathrm{H}$-scores were summarized using means, medians, and standard deviations (SD). Statistical analysis was performed using $\mathrm{R}$ [17]. Mixed-effects linear regression was used to examine the differences between the experimental conditions. The duplo experiments and the two observers were treated as two-by-two clustered observations within the experimental conditions. A $p$ value of $<0.05$ was considered to be statistically significant.

\section{Results}

DLL3 IHC was positive in the cell lines at the expected intensity: A549 was negative with occasionally a few dots around the nucleus at the highest magnification $(\times 40)$ (Fig. 1a), most probably a physiological staining in endoplasmic reticulum
$[2,17]$. DLL3 staining in H69 and H82 cell lines was granular cytoplasmatic with higher DLL3 intensity in H82 and low in H69 (Fig. 1b, c). We found a significant difference in DLL3 staining between in duplo experiments (mean $\mathrm{H}$ score of experiment 1 was 94, $\mathrm{SD}=103$, mean $\mathrm{H}$ score and $\mathrm{SD}$ of experiment 2 was $88, \mathrm{SD}=102 p=0.002$ ) and the scores of two investigators (mean $\mathrm{H}$ score investigator 1 was $97 \mathrm{SD}=105$, mean $\mathrm{H}$ score investigator 2 was $86 \mathrm{SD}=101, p=0.0001$ ). Since these differences were systematic and comparable in all experimental conditions (Supplementary Fig. 1 and 2), we averaged the $\mathrm{H}$-scores per condition.

The differences between the 25 tested experimental conditions (as listed in Table 1) were statistically significant $(p<0.0001)$ with the interclass correlations between the $\mathrm{H}$ scores within the conditions of 0.59 for $\mathrm{H} 69$ and 0.77 for $\mathrm{H} 82$.

\section{Variation in fixatives and fixation times}

All three cell lines were subjected to fixation in $10 \%$ neutral buffered formalin and CytoLyt (Fig. 2a) for four different times $(3,24,48$, and $72 \mathrm{~h})$. Formalin fixation of $24 \mathrm{~h}$ showed the highest $\mathrm{H}$-scores and was considered the golden standard for further experiments. Fixation time of $3 \mathrm{~h}$ in formalin was already sufficient, and DLL3 staining was comparable after longstanding fixation (48 and $72 \mathrm{~h})(p=0.33$ for H82; $p=$

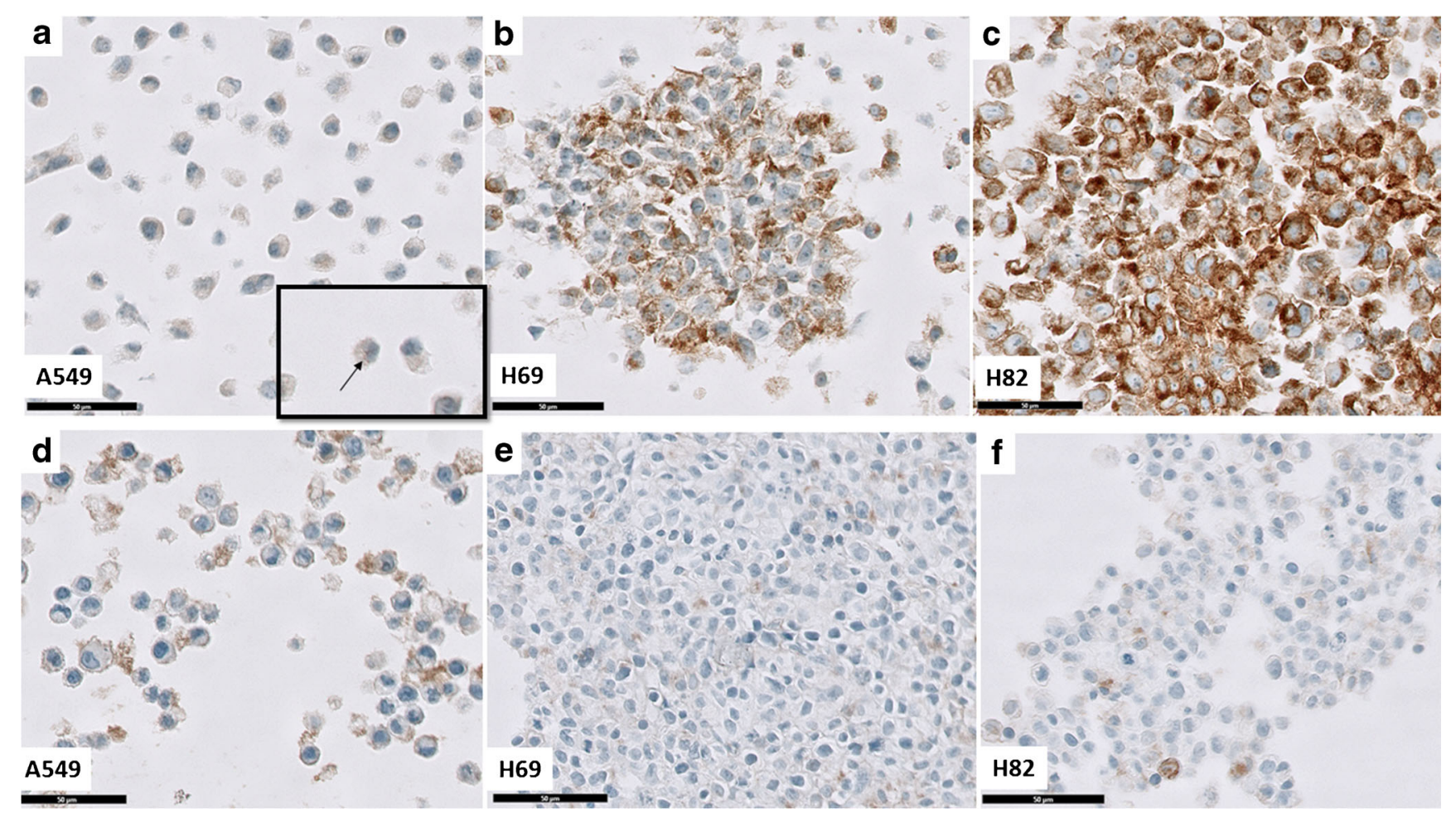

Fig. 1 a-c DLL3 IHC staining ( $\times 40$ magnification, black bar down left $50 \mu \mathrm{m})$ in the cell lines using the optimal fixation method ( $24 \mathrm{~h}$ in $10 \%$ buffered formalin). A549 was negative for DLL3 with few dots occasionally noted around the nucleus (arrow). Note the fine granular cytoplasmic positivity at intermediate (H69) and high (H82) intensity level. d-f DLL3 staining in the cell lines after decalcification in Sakura. Note the artefactual membranous positivity in A549 (d). Also note a significant reduction in DLL3 staining in H69 and H82 when compared to the optimal fixation method $(\mathbf{b}, \mathbf{c})$ 


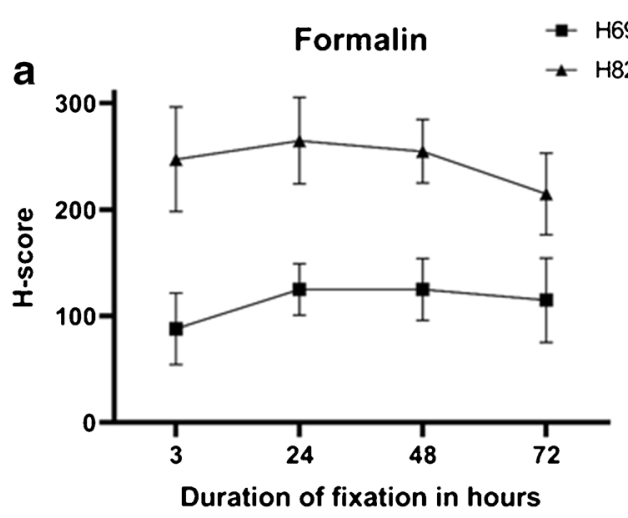

Duration of fixation in hours

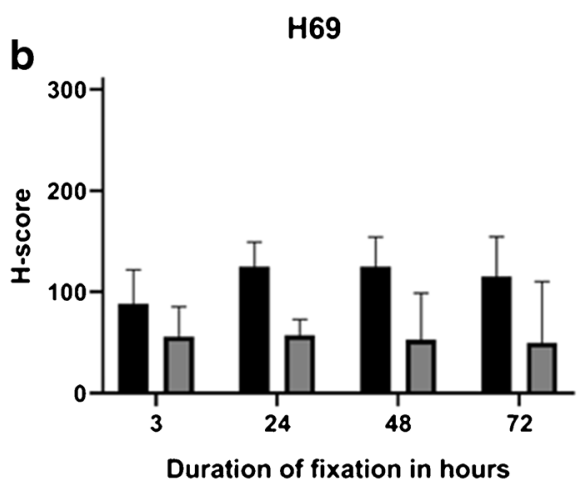

Fig. 2 a, b DLL3 IHC intensity (mean and SD of H-score, $x$ axis) after different fixation times (in hours, $y$ axis) in formalin (black bars) and Cytolyt (gray bars) plotted for both cell lines. Note the lower DLL3 intensity after fixation in Cytolyt whereas the difference became larger in the medium/low DLL3 intensity cell line (H69) and increases with fixation time in Cytolyt. Note also the maximal intensity after $24 \mathrm{~h}$ of formalin fixation, considered as a golden standard for further

0.28 for H69). Overall, DLL3 staining was lower after Cytolyt fixation compared with formalin in both cell lines in all conditions with the difference becoming more prominent after Cytolyt fixation of longer than $24 \mathrm{~h}(p=0.0021$ for H82; $p<0.001$ for H69).

\section{Influence of formalin postfixation after CytoLyt}

The influence of postfixation in formalin was examined after the initial fixation in CytoLyt for three different times: $3 \mathrm{~h}$ CytoLyt followed by 24 -h formalin $(3 \mathrm{C}+24 \mathrm{~F}$, see Table 1$)$; 24-h CytoLyt followed by 3 -h formalin $(24 \mathrm{C}+3 \mathrm{~F})$; and $24 \mathrm{~h}$ $(24 \mathrm{C}+24 \mathrm{~F}$, see Table 1) of formalin postfixation (Fig. 2b). We showed that postfixation in formalin for $24 \mathrm{~h}$ restored to a certain extent the IHC intensity irrespective of the duration of Cytolyt prefixation (three or $24 \mathrm{~h}: p=0.0349$ for H69; $p=$ 0.59 for H82) but not to the level of the golden standard ( $24 \mathrm{~h}$ formalin fixation), although the differences were not statistically significant but showed a certain trend $(p=0.063)$. Interestingly, we noted a larger difference in the low-DLL3 expression cell line H69.

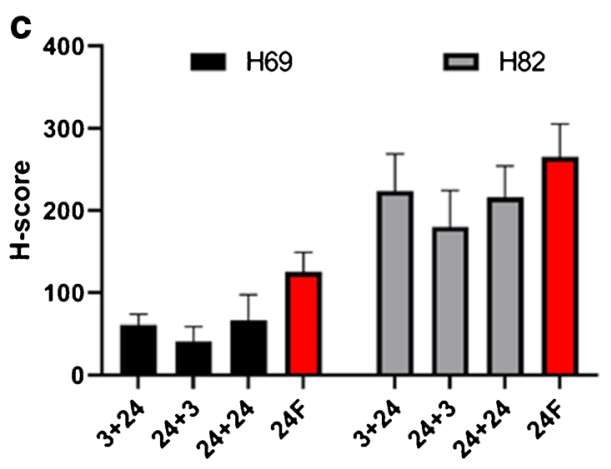

Duration of fixation in hours (Cyt+Form)

H82

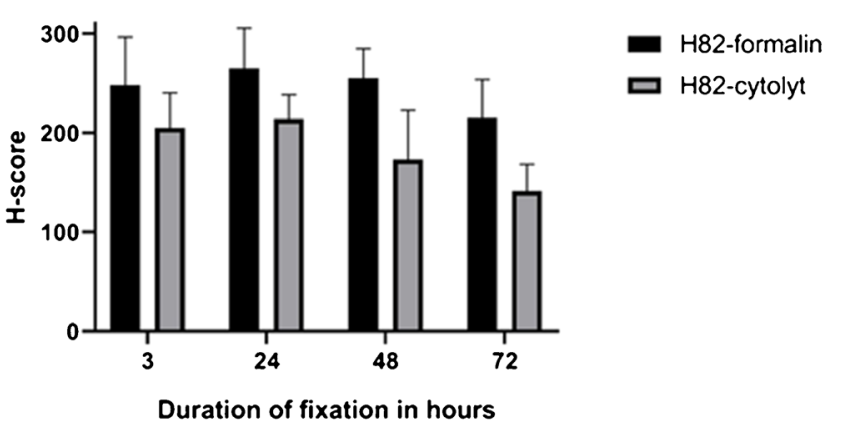

experiments. c DLL3 IHC intensities (H-score, $x$ axis) plotted per positive cell line after initial fixation in Cytolyt and postfixation in formalin for different times ( $y$ axis). Per time point Cytolyt and formalin times are depicted. In red column, the intensity of the same cell line after $24 \mathrm{~h}$ of formalin fixation (golden standard). Note how DLL3 intensity could be partially restored by postfixation in formalin of $24 \mathrm{~h}$

\section{Postponed fixation}

Cells were centrifuged, washed, and left without bovine serum and without fixative for 3,6 , and $24 \mathrm{~h}$ on room temperature and $4{ }^{\circ} \mathrm{C}$ followed by the golden standard fixation time of $24 \mathrm{~h}$ formalin (Suppl Fig. 3). There were no differences observed, irrespective of the duration of fixation postponement $(p=0.23$ for $\mathrm{H} 69 ; p=0.70$ for H82) or the temperature ( $p=0.55$ for $\mathrm{H} 69 ; p=0.74$ for $\mathrm{H} 82$ ).

\section{Decalcification}

Different times of formalin fixation were followed by two times of decalcification ( 24 and $48 \mathrm{~h}$ ) using the two decalcification methods (Kristensen and Sakura). We showed that decalcification in Kristensen did not lead to decrease in DLL3 staining intensity (Fig. 3a) $(p=0.50)$. In contrast, decalcification in Sakura led to significant decrease in DLL3 intensity in all tested times (Fig. 3b) $(p<0.0001$ and $p<0.0001$ at $24 \mathrm{~h}$ for H69; $p=0.0004$ at $24 \mathrm{~h}$ and $p=0.0006$ at $48 \mathrm{~h}$ for H82). Moreover, we observed an artefactual positivity in the DLL3 


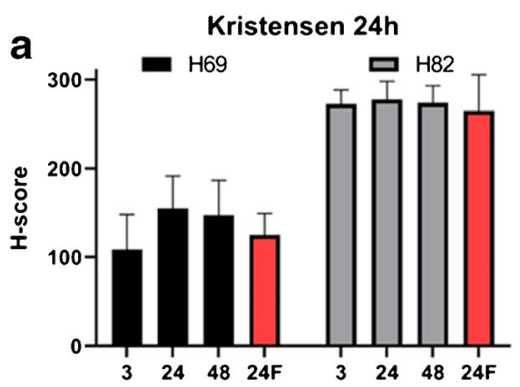

Fixation in formalin followed by $24 \mathrm{~h}$ in Kristensen

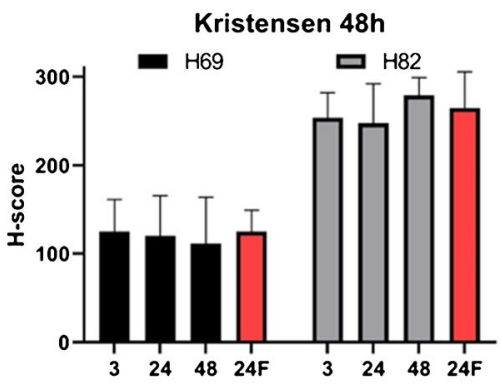

Fixation in formalin followed by $48 \mathrm{~h}$ in Kristensen

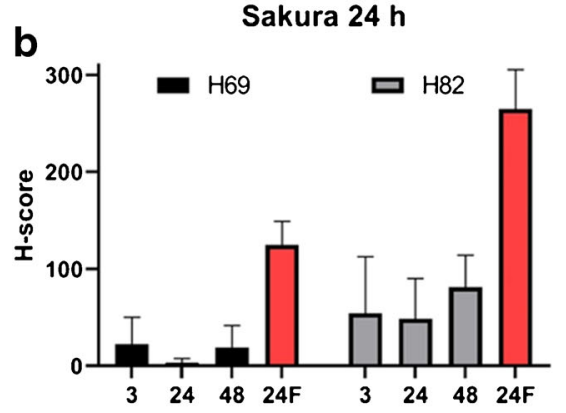

Fixation in formalin followed by $24 \mathrm{~h}$ in Sakura

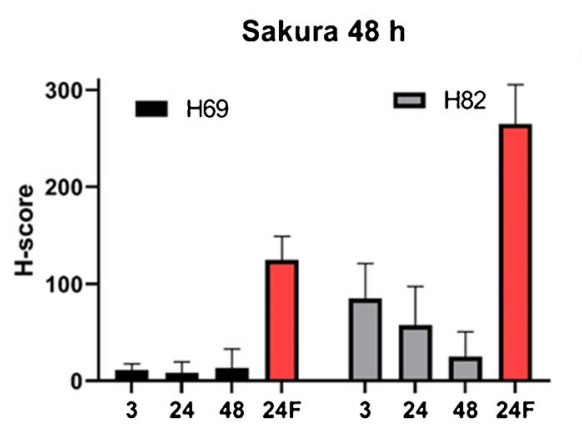

Fixation in formalin followed by $48 \mathrm{~h}$ in Sakura

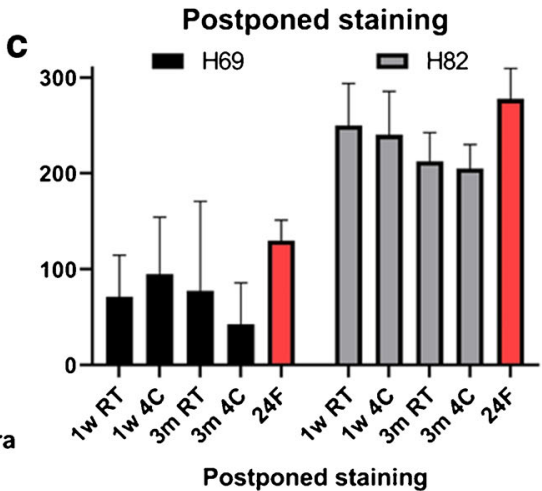

Fig. 3 DLL3 staining intensity (mean and SD of H-score, $x$ axis) after decalcification for 24 and $48 \mathrm{~h}$ tested on high expressing (H82) and low (H69) DLL3 expressing cell lines with a Kristensen and b Sakura decalcification procedure. Cells underwent different formalin fixation

negative cell line (A549) after Sakura decalcification of any duration (Fig. 1b). The staining was membranous but not cytoplasmatic granular as in the DLL3 positive cell lines under normal conditions. In the same figure, we demonstrate the influence of Sakura decalcification on DLL3 intensity of DLL3 positive cell lines.

\section{Postponed staining}

Postponement of IHC of blanc slides left unstained of either 1 week or 3 months led to a decrease of the DLL3 staining intensity which was statistically non-significant $(p=0.51$ for H69; $p=0.31$ for H82) (Fig. 3c). The difference was slightly larger after 3 months of staining postponement. Interestingly, temperature at which blanc slides were stored (room temperature or $4{ }^{\circ} \mathrm{C}$ ), resulted in a similar (statistically non-significant: $p=0.81$ for H69, $p=0.49$ for H82) decrease in staining intensity.

\section{Discussion}

The influence of preanalytical variables on the staining intensity of DLL3 IHC revealed that formalin fixation of $24 \mathrm{~h}$ led to an optimal performance of DLL3 IHC staining and that longstanding fixation with Cytolyt as well as decalcification times, shown in hours on the $x$ axis. c DLL3 staining after postponed staining of blanc slides for 1 week or 3 months at room temperature (RT) or 4C ( $y$ axis). In every panel DLL3 staining after optimal fixation is shown in red $(24 \mathrm{~F})$

using Sakura Reagent TDE30 decalcifier resulted in essential reduction of DLL3 staining intensities.

From what is reported in the literature, the diagnosis of SCLC is made on cytology samples in 15-31\% patients as many patients have a broadly metastasized disease at the time of diagnosis [18]. These percentages may vary even more in the clinical practice then reported in the literature. Fixation in Cytolyt, preservative solution used in our institution, resulted in overall lower DLL3 IHC intensities than formalin-fixed cell lines. The contents of the fine needle aspiration are typically expelled and rinsed in a cell preservative solution, in order to assure sufficient material for acquisition of a cell block for IHC [19]. In daily practice, a fine needle aspirate is preserved in Cytolyt, a methanol-based fixative, until a cell block is made for immunocytochemistry. During this last step, the samples are commonly subjected to formalin postfixation before being embedded in paraffin [20]. In an experiment mimicking this situation, reduced DLL3 intensity after Cytolyt fixation alone, could partially be restored by postfixation for $24 \mathrm{~h}$ in neutral buffered formalin. In a comparable study on PD-L1 IHC after different fixation methods, Cytolyt-fixed cytology samples and histology samples from the same tumor had comparable percentage of positive tumor cells in PD-L1 IHC when the tissue block is made using agar-based technique where formalin fixation of the embedded cells is one of the steps [21]. In contrast, when only methanol-based fixative was 
used (Celient technique), cytology samples were proportionally more often PD-L1 negative compared to their histological control [21]. Our experiment and these data support the finding that formalin (post)fixation is essential for the optimal performance of DLL3 IHC.

Antigen retrieval is an important step in the process of immunohistochemistry and is mainly based on heating induced protein modifications in order to release the antigen from methylene bridges formed between the proteins by formalin [22]. Some antigen retrieval procedures include $\mathrm{pH}$ modifications during heating in order to enhance the effect $[23,24]$. In case of alcohol-based fixatives, proteins undergo coagulation instead of forming of methylene bridges, and antigen retrieval developed for formalin-fixed tissues is ineffective resulting in lower IHC intensities [25]. Our findings indicate that predictive immunohistochemistry should be validated on cytology samples and that formalin fixation of cytology samples leads to improvement. It remains to be investigated whether these lower DLL3 intensities in cytology fixative are clinically relevant. After showing promising results in phase 1 and 2 trials [26-28], Rova-T, a monoclonal antiDLL3 antibody-drug conjugate, failed to prove therapeutic benefit in phase 3 trials $[27,28]$. Currently, DLL3 is being investigated in a phase 1 trial using bispecific $\mathrm{T}$ cell engager (BiTE) antibody construct targeting DLL3 [29], a T cell redirecting immunotherapy. BiTE is designed to transiently connect DLL3-positive cells to CD3-positive $T$ cells and induce $T$ cell-mediated cell lysis and concomitant $\mathrm{T}$ cell proliferation.

We also demonstrated that type of decalcification can drastically decrease the performance of the IHC. Sakura is currently used in small biopsies for short decalcification (1-2 h) and contains a mix of formic acid and hydrochloric acid with $\mathrm{pH}$ of 0.1 [30]. The Kristensen method is based on a mix of formic acid and its sodium salt, sodium formate, and has a higher $\mathrm{pH}=2.2$, and is used for larger bone fragments which need longstanding decalcification [31]. This difference in acidity may be a reason for the better performance of Kristensendecalcified samples. It should be noted that in our experiments, a longer Sakura decalcification time was applied than recommended by the Sakura manufacturer, and should be avoided in the daily practice. Artefactual positivity of the DLL3 negative cell line after Sakura decalcification is an important finding for the clinical practice. Our results indicate that IHC, especially the predictive IHC, should be validated using different methods of decalcification. It should be noted though that our study did not include all the decalcifying methods, as for example, the ethylenediaminetetracetic acid (EDTA) which is commonly used for small biopsies by pathology laboratories and has a higher $\mathrm{pH}$.

In our previous work, we demonstrated that postponed fixation of lung resection specimens resulted in a significant reduction of different IHC as cytokeratins, TTF1, but most importantly of PD-L1 [8]. The proportion of PD-L1-positive samples reduced dramatically with the duration of cold ischemia. In the clinical practice, predictive IHC variability can lead to patients not be considered eligible for immune therapy and checkpoint inhibitors [32]. Interestingly, DLL3 was not sensitive for postponed fixation (cold ischemia). Possibly, the DLL3 protein is relatively stable over time, although the protein half-life is not known. Another explanation could be that the cell lines are less sensitive to cold ischemia due to the lack of the tissue context with inflammatory cells and stroma which produce and release degrading enzymes.

Postponed staining reduced the performance of the DLL3 staining irrespective of the temperature at which the blanc slides were kept. After the slides of $4 \mu \mathrm{m}$ are cut and put on the glass, tissue is exposed to oxygen from the air. We hypothesize that oxidation of the proteins might lead to reduced staining, as described earlier [33]. Although this experiment was not statistically significant, it might prove clinically relevant depending on the thresholds of DLL3 positivity in the clinical trials. Interestingly, in another study, when postponed IHC was investigated on 32 IHC markers (postponement of blanc slides staining up to 1 year), four of 32 IHC markers showed reduced staining when the blanc slides were kept at 4C compared with 11 and 21 markers with reduced staining when the slides were kept on respectively room temperature and $37 \mathrm{C}$, indicating that epitope stability of some IHC markers is dependent on the temperature [34].

Notably, most differences between the conditions were observed in the H69 cell line, which has a low DLL3 epitope concentration. Samples with low epitope concentration (critical samples) are considered optimal for validation of novel IHC tests for an equivalent outcome compared to the clinically validated test, because a slight variation in the test can lead to the altered outcome $[32,35]$. This is in contrast to the samples with high epitope concentration, which will reach the maximum staining irrespective of the slight variations in the test used. Similarly, H69 cell line could be considered a "critical sample" for preanalytical conditions testing and their influence on DLL3 IHC. Differences between the conditions were more easily detected in a cell line with a low DLL3 epitope concentration.

In conclusion, formalin fixation of $24 \mathrm{~h}$ led to the most optimal results of DLL3 IHC. Acceptable staining was reached already after $3 \mathrm{~h}$ of formalin fixation. Fixation in Cytolyt, longstanding decalcification using Sakura, and postponed staining of blanc slides led to decreased DLL3 IHC. It remains to be determined whether these differences will be clinically relevant when DLL3 is implemented in the clinical practice.

Contributions ET and TR designed the study, AHZ performed the statistical analysis, TR and ET generated the data and analyzed the data. SD, PM, and VW optimized and performed the experiments.

Funding information This study was supported by an investigator initiated grant to ET and TR from Abbvie, Chicago, Ill., USA. 


\section{Compliance with ethical standards}

Conflict of interest TR contributed to advisory boards of Abbvie and Roche (fee to the institution) and received a travel grant from Takeda. ET contributed to advisory boards of Abbvie.

WV, PK and SD declare no conflicts of interest.

This research was performed on the cell lines only and no human or animal material was involved.

Open Access This article is licensed under a Creative Commons Attribution 4.0 International License, which permits use, sharing, adaptation, distribution and reproduction in any medium or format, as long as you give appropriate credit to the original author(s) and the source, provide a link to the Creative Commons licence, and indicate if changes were made. The images or other third party material in this article are included in the article's Creative Commons licence, unless indicated otherwise in a credit line to the material. If material is not included in the article's Creative Commons licence and your intended use is not permitted by statutory regulation or exceeds the permitted use, you will need to obtain permission directly from the copyright holder. To view a copy of this licence, visit http://creativecommons.org/licenses/by/4.0/.

\section{References}

1. Chapman G, Sparrow DB, Kremmer E, Dunwoodie SL (2011) Notch inhibition by the ligand DELTA-LIKE 3 defines the mechanism of abnormal vertebral segmentation in spondylocostal dysostosis. Hum Mol Genet 20:905-916. https://doi.org/10.1093/ hmg/ddq529

2. Geffers I, Serth K, Chapman G, Jaekel R, Schuster-Gossler K, Cordes R, Sparrow DB, Kremmer E, Dunwoodie SL, Klein T, Gossler A (2007) Divergent functions and distinct localization of the Notch ligands DLL1 and DLL3 in vivo. J Cell Biol 178:465476. https://doi.org/10.1083/jcb.200702009

3. Ito T, Kudoh S, Ichimura T, Fujino K, Hassan WAMA, Udaka N (2017) Small cell lung cancer, an epithelial to mesenchymal transition (EMT)-like cancer: significance of inactive Notch signaling and expression of achaete-scute complex homologue 1. Hum Cell 30:1-10. https://doi.org/10.1007/s13577-016-0149-3

4. Saunders LR, Bankovich AJ, Anderson WC et al (2015) A DLL3targeted antibody-drug conjugate eradicates high-grade pulmonary neuroendocrine tumor-initiating cells in vivo. Sci Transl Med 7: 302ra136. https://doi.org/10.1126/scitranslmed.aac9459

5. Brunnström H, Johansson A, Westbom-Fremer S, Backman M, Djureinovic D, Patthey A, Isaksson-Mettävainio M, Gulyas M, Micke P (2017) PD-L1 immunohistochemistry in clinical diagnostics of lung cancer: inter-pathologist variability is higher than assay variability. Mod Pathol 30:1411-1421. https://doi.org/10.1038/ modpathol.2017.59

6. Torlakovic E, Lim HJ, Adam J et al (2020) "Interchangeability" of PD-L1 immunohistochemistry assays: a meta-analysis of diagnostic accuracy. Mod Pathol 33(1):4-17. https://doi.org/10.1038/ s41379-019-0327-4

7. Lloyd IE, Zhou W, Witt BL, Chadwick BE (2019) Characterization of PD-L1 immunohistochemical expression in cell blocks with different specimen fixation and processing methods. Appl Immunohistochem Mol Morphol 27:107-113. https://doi.org/10. 1097/PAI.0000000000000572

8. van Seijen M, Brcic L, Gonzales AN et al (2019) Impact of delayed and prolonged fixation on the evaluation of immunohistochemical staining on lung carcinoma resection specimen. Virchows Arch 475:191-199. https://doi.org/10.1007/s00428-019-02595-9
9. Portier BP, Wang Z, Downs-Kelly E, Rowe JJ, Patil D, Lanigan C, Budd GT, Hicks DG, Rimm DL, Tubbs RR (2013) Delay to formalin fixation 'cold ischemia time': effect on ERBB2 detection by in-situ hybridization and immunohistochemistry. Mod Pathol 26:19. https://doi.org/10.1038/modpathol.2012.123

10. Forest F, Cote G, Laville D et al (2019) Impact of delayed fixation and decalcification on PD-L1 expression: a comparison of two clones. Virchows Arch:693-699. https://doi.org/10.1007/s00428019-02613-w

11. Buesa RJ, Peshkov MV (2012) How much formalin is enough to fix tissues? Ann Diagn Pathol 16:202-209. https://doi.org/10.1016/j. anndiagpath.2011.12.003

12. Tsao MS, Kerr KM, Yatabe Y, Hirsch FR International Association for the Study of Lung Cancer edited by IASLC Atlas of PD-L1 immunohistochemistry testing in lung cancer conquering thoracic cancers worldwide

13. Yatabe Y, Dacic S, Borczuk AC, Warth A, Russell PA, Lantuejoul S, Beasley MB, Thunnissen E, Pelosi G, Rekhtman N, Bubendorf L, Mino-Kenudson M, Yoshida A, Geisinger KR, Noguchi M, Chirieac LR, Bolting J, Chung JH, Chou TY, Chen G, Poleri C, Lopez-Rios F, Papotti M, Sholl LM, Roden AC, Travis WD, Hirsch FR, Kerr KM, Tsao MS, Nicholson AG, Wistuba I, Moreira AL (2019) Best practices recommendations for diagnostic immunohistochemistry in lung cancer. J Thorac Oncol 14:377-407. https://doi. org/10.1016/j.jtho.2018.12.005

14. Strickland AL, Blacketer S, Molberg K, Markantonis J, Lucas E (2019) Effects of decalcifying agents of variable duration on PD-L1 immunohistochemistry. Am J Clin Pathol 153:258-265. https://doi. org/10.1093/ajcp/aqz161

15. Sharma SK, Pourat J, Abdel-Atti D et al (2017) Non-invasive interrogation of DLL3 expression in metastatic small cell lung cancer. Cancer Res.0299.2017. https://doi.org/10.1158/0008-5472.CAN17-0299

16. Calculating H-Score - The ASCO Post. https://www.ascopost.com/ issues/april-10-2015/calculating-h-score/. Accessed 21 Dec 2019

17. The R Foundation (2018) R: The R Project for Statistical Computing. https://www.r-project.org/. Accessed 5 May 2020

18. Gansler T, Fedewa SA, Lin CC, Jemal A, Ward EM (2016) Variations in cancer centers' use of cytology for the diagnosis of small cell lung carcinoma in the National Cancer Data Base. Cancer Cytopathol 124:44-52. https://doi.org/10.1002/cncy.21610

19. Roh MH (2015) The utilization of cytologic fine-needle aspirates of lung cancer for molecular diagnostic testing. J Pathol Transl Med 49:300-309. https://doi.org/10.4132/jptm.2015.06.16

20. Jain D, Mathur SR, Iyer VK (2014) Cell blocks in cytopathology: a review of preparative methods, utility in diagnosis and role in ancillary studies. Cytopathology 25:356-371

21. Hart NAT, van der Starre-Gaal J, Vonk JM, Timens W (2019) Essential preanalytics in PD-L1 immunocytochemistry. Histopathology 74:362-364

22. Sompuram SR, Vani K, Messana E, Bogen SA (2004) A molecular mechanism of formalin fixation and antigen retrieval. Am J Clin Pathol 121:190-199. https://doi.org/10.1309/ BRN7CTX1E84NWWPL

23. Shi S-R, Shi Y, Taylor CR (2011) Antigen retrieval immunohistochemistry. J Histochem Cytochem 59:13-32. https://doi.org/10. 1369/jhc.2010.957191

24. Yamashita S (2010) PH or ionic strength of antigen retrieval solution: a potential role for refolding during heat treatment. In: Antigen retrieval immunohistochemistry based research and diagnostics. Wiley, Inc., Hoboken, pp 303-321

25. Werner M, Chott A, Fabiano A, Battifora H (2000) Effect of formalin tissue fixation and processing on immunohistochemistry. Am J Surg Pathol 24(7):1016-1019

26. Carbone DP, Morgensztern D, Le Moulec S et al (2018) Efficacy and safety of rovalpituzumab tesirine in patients with DLL3- 
expressing, $\geq 3$ rd line small cell lung cancer: results from the phase 2 TRINITY study. J Clin Oncol 36:8507-8507. https://doi.org/10. 1200/jco.2018.36.15_suppl.8507

27. Komarnitsky P, Lee H-J, Shah M et al (2017) 1537TiPA phase 3 trial of rovalpituzumab tesirine vs topotecan in patients with advanced small cell lung cancer following frontline platinum-based chemotherapy. Ann Oncol 28. https://doi.org/10.1093/annonc/ $\mathrm{mdx} 386.010$

28. Abbvie AbbVie announces results from phase 2 study evaluating rovalpituzumab tesirine (Rova-T) for third-line treatment of patients with DLL3-expressing relapsed/refractory small cell lung cancer. In: Abbvie News Cent. https://news.abbvie.com/news/abbvieannounces-results-from-phase-2-study-evaluating-rovalpituzumabtesirine-rova-t-for-third-line-treatment-patients-with-d113expressing-relapsedrefractory-small-cell-lung-cancer.htm. Accessed 12 Aug 2019

29. Smit M-AD, Borghaei H, Owonikoko TK, Hummel HD, Johnson ML, Champiat S, Salgia R, Udagawa H, Boyer MJ, Govindan R (2019) Phase 1 study of AMG 757, a half-life extended bispecific T cell engager (BiTE) antibody construct targeting DLL3, in patients with small cell lung cancer (SCLC). J Clin Oncol 37:TPS8577. https://doi.org/10.1200/JCO.2019.37.15_suppl.TPS8577

30. B.V. SFE (2016) SAKURA REAGENT TDE 30 DECALCIFIER. $1-10$
31. Kristensen HK (1948) An improved method of decalcification. Stain Technol 23:151-154. https://doi.org/10.3109/ 10520294809106242

32. Butter R, Hart't NA, Hooijer GKJ et al (2019) Multicentre study on the consistency of PD-L1 immunohistochemistry as predictive test for immunotherapy in non-small cell lung cancer. J Clin Pathol. https://doi.org/10.1136/jclinpath-2019-205993

33. Blind C, Koepenik A, Pacyna-Gengelbach M, Fernahl G, Deutschmann N, Dietel M, Krenn V, Petersen I (2008) Antigenicity testing by immunohistochemistry after tissue oxidation. J Clin Pathol 61:79-83. https://doi.org/10.1136/jcp.2007. 047340

34. Van den Broek LJCM, Van de Vijver MJ (2000) Assessment of problems in diagnostic and research immunohistochemistry associated with epitope instability in stored paraffin sections. Appl Immunohistochem Mol Morphol 8:316-321. https://doi.org/10. 1097/00022744-200012000-00009

35. Thunnissen E, de Langen AJ, Smit EF (2017) PD-L1 IHC in NSCLC with a global and methodological perspective. Lung Cancer 113:102-105

Publisher's note Springer Nature remains neutral with regard to jurisdictional claims in published maps and institutional affiliations. 